\title{
musanow
}

\section{Dietary protein lowers blood pressure}

Increased dietary protein intake decreases blood pressure in individuals with overweight and untreated hypertension, shows a study published in the American Journal of Clinical Nutrition.

Previous randomized trials assessing the effects of dietary protein on blood pressure have produced conflicting results. Karianna Teunissen-Beekman and colleagues carried out a new randomized, double-blind, parallel study to compare the effect of a protein-supplemented diet with that of a carbohydrate-supplemented diet on blood pressure control.

Study participants were overweight (BMI $\left.25-35 \mathrm{~kg} / \mathrm{m}^{2}\right)$ and had upperrange prehypertension or grade I hypertension (systolic blood pressure 130-159 $\mathrm{mmHg}$ and diastolic blood pressure 85-99 $\mathrm{mmHg}$ ). Among the 94 patients who completed the study, 43 received a mixed protein supplement and 51 received a supplement containing the carbohydrate maltodextrin over a 4-week period. The two diets were weightmaintaining and isocaloric.
The primary outcomes were office and daytime blood pressure, which did not differ between groups initially. Increased protein intake significantly reduced office systolic and diastolic blood pressure and daytime systolic blood pressure by $4.9 \pm 1.7$, $2.7 \pm 1.3$ and $4.6 \pm 1.7 \mathrm{mmHg}$, respectively, compared with carbohydrate intake.

The investigators found that urinary sodium excretion in the carbohydrate group was higher than in the protein group, which is a possible confounding factor of the study, as sodium intake is positively associated with blood pressure.

Teunissen-Beekman points out that the results of the study are important for public health, as even a small reduction in blood pressure may lead to considerable health benefits at the population level.

Lian Evans

Original article Teunissen-Beekman, K. F. et al. Protein supplementation lowers blood pressure in overweight adults: effect of dietary proteins on blood pressure (PROPRES), a randomized trial. Am. J. Clin. Nutr. doi:10.3945/ajcn.111.029116 